\title{
Copper recovery from PCBs by Acidithiobacillus ferrooxidans: Toxicity of bioleached metals on biological activity
}

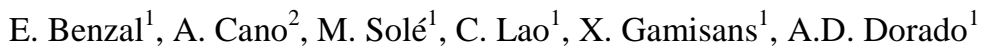

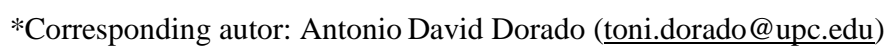 \\ ORCID numbers of the authors E. Benzal (0000-0002-0045-1341), M. Solé (0000-0002-0854-4649), C. Lao (0000- \\ 0002-7342-7801), X. Gamisans (0000-0003-1856-8692) and A.D. Dorado (0000-0003-0238-5867)
${ }^{1}$ Department of Mining, Industrial and ICT Engineering, Universitat Politècnica de Catalunya, 08242 Manresa (Barcelona), Spain
${ }^{2}$ Faculty of exact, natural and agricultural sciences, Universidad de Santander, 680003 Bucaramanga \\ (Santander), Colombia
}

Keywords: Biological leaching, electronic waste, printed circuit boards, valorisation, column, respirometry

\begin{abstract}
The suitability and limits of bioleaching for copper recovery from printed circuits boards has been stated with new strategies and methodologies. The process has been tested using a continuous column reactor simulating those conditions found at industrial scale. The new strategy developed improved the kinetic reaction rate and overcomes transport limitations for the leaching solution, thus improving copper recoveries from $50 \%$ to $80 \%$ in only 6 hours. This drastically reduced the time required by previous studies to achieve the same copper recovery. Inhibition effects of the biological process due to the release of metals from E-waste has been identified by means of microrespirometric monitoring tests. This systematic study allowed identifying that nickel, copper and aluminum impact the microorganisms' activity, inactivating them in specific scenarios (depending on the concentration and the time exposed). Including the time exposure as variable, this work demonstrated that metal concentrations that have been reported as non-toxic to microorganisms, resulted toxic when the required leaching contact time was considered. Besides high iron concentrations also produce inhibitory effect on the microorganisms' growth, despite being the energy source for their metabolism.
\end{abstract}

\section{Graphical abstract}

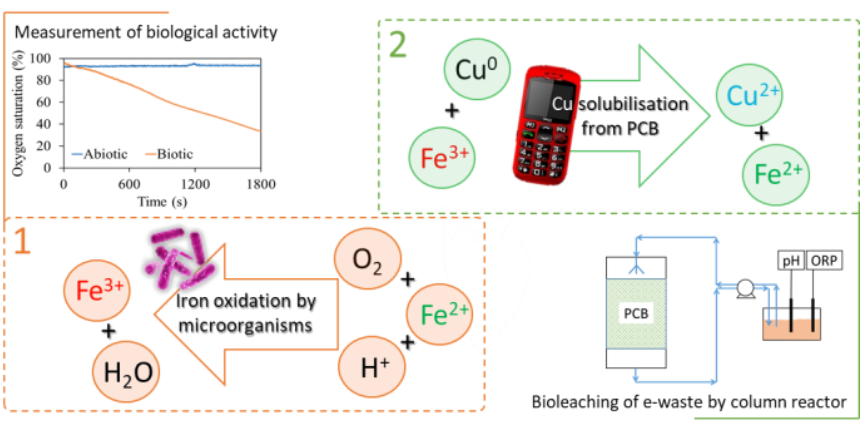

\section{Acknowledgments}

This work has been founded by the project 2016LLAV00034 founded by AGAUR and FEDER funds. Eva Benzal gratefully acknowledges a FPU-2014 predoctoral scholarship from Ministerio de Educación, Cultura y Deporte (Spain) and co-financed by FEDER funds. 
2 Bioleaching has gained importance over the past few years as a sustainable alternative for metals recovery

3 from E-waste. The current aim is to recover valuable metals at competitive speed with lower energetic 4 expenditure and lower environmental impact. In this context, different strategies have been tested to 5 increase the efficiency of copper recovery from E-waste. Given the complex composition of the E-waste, 6 the metals solubilized in the process could affect the biological process, inhibiting the activity of the 7 microorganisms. Therefore, the toxic effect that some bioleached metals have on the microorganisms has 8 been also evaluated. Although this aspect is not usually taken into account when the bioextraction process is studied, this could limit the applicability of the technology.

\section{INTRODUCTION}

Over recent decades, both rapid technology development and ever-shortening lifespans have contributed to increase the need for electronic waste (E-waste) disposal. E-waste is the type of waste that is increasing at the highest rate, which is estimated to be around 3-5\% per year, according to the WHO[1]. The recycling process of E-waste is particularly hard because of its complex structure and heterogeneous blend of organic materials, metals and ceramics (around 30\% of plastics, 30\% of refractory materials and up to $40 \%$ of metals on average) [2-5]. Some of these metals are highly valuable such as copper, silver or gold, which could be retrieved for new uses. At an industrial scale, there are two main processes which are used to recover these metals, called pyrometallurgical and hydrometallurgical processes. However, they are characterized by using high temperatures and aggressive chemicals to melt or remove the matrix containing the metals, therefore generating an important economic cost and a large environmental impact. Bioleaching, an environmentally friendly recycling technology, has been tested as an alternative to these methods, especially in the mining field for low-grade ores [6]. The bioleaching technique is based on the activity of microorganisms that are able to regenerate the leaching agent responsible for the extraction of the metal.[7, 8]. For copper extraction, this process is based on the action of iron (III), which oxidizes metallic copper in the electronic scrap, transforming it into soluble copper (II) and in turn, the iron is reduced to iron (II). The role of the microorganisms is to reoxidise iron (II), closing the loop in a cyclic process (Fig. 1. Eq 1).

Bio-heap processes most frequently used in commercial applications, especially for metal recovery from low-grade ores and mineral concentrates $[9,10]$. This technique could be also effective to recover metals from E-waste at an industrial scale. Column leaching is used to simulate heap or dump leaching processes at a laboratory scale, allowing the optimization of the process [11-13]. However, there is not much information about column reactors in e-waste bioleaching studies [11, 14, 15]. Metal recovery from electronic scrap by bioleaching has been previously studied, basically in batch conditions using stirring flasks [11, 12, 16-18]. Column studies give rise to new challenges since good contact between the material and the leaching agent must be ensured, overcoming mass transfer limitations. Furthermore, as mentioned above, the column reactor is more suitable for scaling-up the process, adapting it to an industrial scale and allowing continuous-mode operation.

More than 60 different elements can be found in the composition of E-waste [19]. Consequently, in a common bioleaching operation, metals different from the metal of interest could also be bioleached during the process, including toxic metals. The presence of these elements in the solution under certain conditions could affect the biological activity [20]. Most bioleaching studies are carried out in only one step, which means that E-waste and inoculum are put together in the appropriate medium under specific conditions. Therefore, iron, copper and other metals to be bioleached are in contact with the biomass [21-23] and could affect the activity of the microorganism. In the case of two step processes, in the first step, the biomass produces the oxidizing reagent, $\mathrm{Fe}(\mathrm{III})$ in a bioreactor. Then, in the second step, the solution containing $\mathrm{Fe}$ (III) is put in contact with the E-waste. As a result, the extracted copper, $\mathrm{Fe}(\mathrm{II})$ and other extracted metals are not in contact with the biomass.

In our work, in order to optimize the bioleaching process and avoid the use of fresh reagents, making the process more economical and environmentally friendly, the bioleachate obtained from E-waste will be recirculated, re-bio-oxidizing its content in Fe(II). However, other metals extracted in the process can be 
recirculated as well, and these metals can affect biomass activity. Therefore, considering the toxic effect of some metals in leaching solutions is a key factor for the proper operation of the bioleaching process.

On the other hand, $\mathrm{Fe}(\mathrm{II})$ is used as suitable energy source by Acidithiobacillus ferrooxidans. This bacteria is one of the few microorganisms that can obtain energy from the oxidation of $\mathrm{Fe}$ (II) to $\mathrm{Fe}$ (III) [24]. However, Barron and Luecking [25] confirmed that substrate (Fe (II)) inhibition could occur. Nevertheless, it is interesting to carry out the bioleaching experiments with the maximum $\mathrm{Fe}$ (II) concentration possible, since this will allow a greater concentration of the leaching agent $(\mathrm{Fe}(\mathrm{III}))$ and, consequently, a greater extraction yield will be achieved. Although this aspect has been studied by some authors, an agreement has not yet been reached on the value of these inhibitory substrate concentrations [25-28]. Whereas Barron and Luecking [25] affirmed that substrate inhibition was obtained when exceeding $3 \mathrm{~g} / \mathrm{L}$ of $\mathrm{Fe}$ (II) in the solution, reaching the maximal inhibition with $20 \mathrm{~g} / \mathrm{L}$ of iron (II), Kelly and Jones [27] reported that concentrations above $39 \mathrm{~g} / \mathrm{L}$ of iron (II) produced the substrate inhibition. Thus, the results focused on substrate inhibition are confusing and a specific range has not been defined yet. In addition, it is noteworthy that the authors focused on this aspect usually determine the inhibition by measuring the iron concentration, without taking into account the exposure time.

In the case of Acidithiobacillus ferrooxidans, one of the most important microorganisms used for copper recovery [29], some studies have been focused on its tolerance to different metals, evaluating the effect that the metal's presence has on the iron bio-oxidation rate, using iron concentrations as a measure of the biomass activity [30-32]. Giebner et al. [33] suggested another approach which consists in quantifying the consumption of the electron acceptor (oxygen) according to Eq. 1.

$4 \mathrm{Fe}^{2+}+4 \mathrm{H}^{+}+\mathrm{O}_{2} \stackrel{\text { Biological activity }}{\longrightarrow} 4 \mathrm{Fe}^{3+}+2 \mathrm{H}_{2} \mathrm{O}$

In this sense, respirometry is a very useful technique for monitoring microorganism's activity, via the measuring and interpretation of biological oxygen uptake rates associated with the biological reactions under well-defined operating conditions. Assessment of the Acidithiobacillus ferrooxidans' biological activity can be carried out by measuring the oxygen consumption after a substrate pulse addition. In this regard, an optode-based technique has been adapted to measure the oxygen consumption of Acidithiobacillus ferrooxidans to determine its metabolic activity. The optode-based technique is characterized by the use of small sample volumes $(1$ or $2 \mathrm{~mL})$, therefore reducing the impact on the system without losing sensitivity in the oxygen measurements. Moreover, this technique also allows the determination of the biological activity in a sample almost at real time, so changes can be made before major issues appear in the system and before the consequences of activity lacking appear.

The aim of the present study was to investigate copper recovery from printed circuit boards in a column reactor, evaluating the bioleaching process to demonstrate the suitability and limits of the technology. In addition, a new strategy was adapted in the column reactor to increase the efficiency of the operation as well as to reduce the time required from several days to a few hours. Furthermore, this work also investigated the potential toxicity of copper, nickel and aluminium, the metals found in greater proportion in the bioleachate, regarding Acidithiobacillus ferrooxidans. This investigation was done by means of microrespirometric measurements regarding concentration and exposed time and its aim was to identify the potential limitation generated by the complex composition of this kind of E-waste. The assays were performed in order to delimit the maximum concentrations tolerated by the microorganisms without negative effects on their metabolism, and to establish the maximum contact time between the metal leaching and biomass. Microrespirometric measurements were also carried out to evaluate the potential inhibition by Fe (II) substrate.

\section{MATERIALS AND METHODS}

\subsection{Electronic scrap}

The printed circuit boards (PCB) used in this study proceed from end-of-life mobile phones (Nokia 3510) collected from the recycling plant Electrorecycling S.A., in Barcelona (Spain). The mobile phones were dismantled manually, removing the batteries, case and other big parts, leaving only the PCB. Then, components such as capacitators and microprocessors were removed and the boards were cut into pieces of about $1 \mathrm{~cm}^{2}$. These pieces were then shredded to reduce the particle size to less than $1 \mathrm{~mm}$ using a lab 
scale knife mill (MF 10 basic, IKA, Germany) and passed through a $1 \mathrm{~mm}$ sieve mesh. The particle size was further fractioned using a $0,2 \mathrm{~mm}$ sieve. The bioleaching tests were conducted with the particles measuring between $0,2 \mathrm{~mm}$ and $1 \mathrm{~mm}$.

The metal content of the scrap was determined by analysing it after acid digestion. Specifically, $0.15 \mathrm{~g}$ of E-waste was digested with $10 \mathrm{~mL}$ of $\mathrm{HNO}_{3}$ : $\mathrm{HCl}(3: 1)$ at $150{ }^{\circ} \mathrm{C}$ for 15 minutes in a microwave (Microwave System, Millestone, Italy). After the digestion, the metal content was analysed by atomic absorption spectroscopy (Solar S2, Thermo Scientific, United States) and ICP-MS (7500CX, Agilent Technologies, United States). The assays were measured in triplicate.

\subsection{Microorganisms and mineral medium}

The bacterial strain Acidithiobacillus ferrooxidans (ATCC 23270) was used. The mineral medium used in the experiments, named $6 \mathrm{~K}$, was prepared as follows: $\left(\mathrm{NH}_{4}\right)_{2} \mathrm{SO}_{4} 3.00 ; \mathrm{K}_{2} \mathrm{HPO}_{4} 0.50 ; \mathrm{MgSO}_{4} \cdot 7 \mathrm{H}_{2} \mathrm{O}$ 0.50; $\mathrm{KCl} 0.10 ; \mathrm{Ca}\left(\mathrm{NO}_{3}\right)_{2} \cdot 4 \mathrm{H}_{2} \mathrm{O} 0.014$ grams were dissolved in $900 \mathrm{~mL}$ of distilled water. The $\mathrm{pH}$ was adjusted with $\mathrm{H}_{2} \mathrm{SO}_{4} 3 \mathrm{~N}$ to $\mathrm{pH} 1.7$ and sterilized by autoclaving $\left(120^{\circ} \mathrm{C} / 20 \mathrm{~min}\right)$ in an autoclave RAYPA AES-75 (Barcelona, Spain). Then, 30 grams of $\mathrm{FeSO}_{4} \cdot 7 \mathrm{H}_{2} \mathrm{O}$ were dissolved in $100 \mathrm{~mL}$ of distilled water and the $\mathrm{pH}$ was adjusted with $\mathrm{H}_{2} \mathrm{SO}_{4} 3 \mathrm{~N}$ to $\mathrm{pH}$ 1.7. This solution was then sterilized by filtration through a $0.22 \mu \mathrm{m}$ syringe filter (GVS - Filter Technology, UK). After that, both solutions were mixed and the $\mathrm{pH}$ was readjusted to $\mathrm{pH} 1.7$ if required.

Acidithiobacillus ferrooxidans was cultivated in a stirrer-tank bioreactor. It was filled with $2 \mathrm{~L}$ of $6 \mathrm{~K}$ mineral medium, containing $10 \%$ of inoculum with a concentration of $6 \cdot 10^{6}$ cell $/ \mathrm{mL}$. The $\mathrm{pH}$ was controlled at $\mathrm{pH} 1.75$ by the dropwise addition of $\mathrm{H}_{2} \mathrm{SO}_{4} 3 \mathrm{~N}$ and the bioreactor was stirred at $200 \mathrm{rpm}$. Moreover, the temperature was maintained at $30{ }^{\circ} \mathrm{C}$ within the reactor jacket using a thermostatic bath. Aeration was achieved by compressed air. Air was sparged through a submerged ceramic diffuser and the airflow rate was set to $50 \mathrm{NL} / \mathrm{h}$ using a rotameter. When the oxidation-reduction potential was up to 600 $\mathrm{mV}$ it was considered that all the iron has been oxidized. Then, $20 \%$ of the total medium was renewed with new $6 \mathrm{~K}$ medium in order to promote the growth of the microorganisms (approximately every 48 hours).

\subsection{Bioleaching experiments in the column reactor}

Column bioleaching was carried out in a $10 \mathrm{~cm}$ high cylindric tube with an internal diameter of $3 \mathrm{~cm}$. The column was filled with $3 \mathrm{~g}$ of electronic scrap mixed with plastic particles between 1 and $3 \mathrm{~mm}$ in diameter. These particles served as structuring in order to provide better solid-liquid contact and avoid wall effect. These plastic particles were obtained by crushing the plastic structure of the mobile phones. Furthermore, a reservoir was incorporated to ease the sampling process and the measurements of $\mathrm{pH}$ and ORP during the experiment. Hence, the reservoir was filled with $400 \mathrm{~mL}$ of the iron (III) solution from the growth bioreactor. As the study was carried out in batch conditions, the iron solution was previously settled, and a supernatant was used. The leaching solution was pumped at a rate of $54 \mathrm{~mL} / \mathrm{min}$ by a peristaltic pump, meaning a rate of $0.13 \mathrm{~cm} / \mathrm{s}$ and a contact time of 23 seconds. Samples for iron and copper measurements were taken every hour from the reservoir, besides measuring $\mathrm{pH}$ and ORP. $\mathrm{pH}$ was controlled at 1.75 by the dropwise addition of $\mathrm{H}_{2} \mathrm{SO}_{4} 3 \mathrm{~N}$.

Copper-ion concentration was analysed with an atomic absorption spectroscopy (Solar S2, Thermo Scientific, United States) whereas total iron and iron (II) determinations were carried out using the 1,10phenantroline method [34] with an UV/VIS spectrophotometer (Lambda 25, PerkinElmer, United States). Oxidation-reduction potential and $\mathrm{pH}$ were measured using a WTW Multi 3620 meter, equipped with a redox (SenTix ORP-T900) and a pH (SenTix 980) sensor (Xylem Analytics, Germany).

\subsection{Toxicity tests development}

Respirometric techniques, based on the rate of oxygen consumption, are an alternative method for monitoring biological activity and it has been chosen in the present work for evaluate the inhibitory effect of metals on Acidithiobacillus ferrooxidans. The optode-based respirometric technique used in this study is characterized by the use of small sample volumes $(1$ or $2 \mathrm{~mL})$ without losing sensitivity in the oxygen measurements, avoiding great impact on the system. 
Toxicity tests were conducted with three different metals, copper, nickel and aluminium, at different concentrations. The selection of these three elements is based on the results obtained in the characterization of the metal composition of the leaching solution after the bioleaching process in previous experiments (Table 1).

Table 1 Analysis of the leaching solution and the bioleached metals found in it after the bioleaching process

\begin{tabular}{cr} 
Metal & Concentration (in ppb) \\
\hline Cu & 1608000.0 \\
Al & 1545.0 \\
Au & 128.8 \\
Co & 545.7 \\
Dy & 3.6 \\
In & 172.6 \\
Ni & 27400.0 \\
Os & 15.8 \\
Pd & 43.2 \\
\hline
\end{tabular}

6

Copper, nickel and aluminium were three bioleached metals in greater quantity. Moreover, Aluminium was also selected because it has also been bioleached in the process but the literature on its toxicity is scarce. These three metals were added as $\mathrm{NiSO}_{4} \cdot 7 \mathrm{H}_{2} \mathrm{O}, \mathrm{CuSO}_{4} \cdot 5 \mathrm{H}_{2} \mathrm{O}$ and $\mathrm{Al}_{2}\left(\mathrm{SO}_{4}\right)_{3} \cdot 18 \mathrm{H}_{2} \mathrm{O}$ in different concentrations between 0.0005 and $1.5 \mathrm{M}$. The particular range for each metal varies from the concentration obtained in the bioleachate to the limit tolerances [35]. In this sense, the concentration range studied for copper was from 0.01 to $1.2 \mathrm{M}$, for nickel it was from 0.005 to $1.5 \mathrm{M}$ and for aluminium it was from 0.001 to $0.50 \mathrm{M}$. For the experiment development, a $500 \mathrm{~mL}$ baffled Erlenmeyer flask was prepared for each metal and concentration. Control experiments were also carried out in the same conditions without the toxic metals. Biological activity was measured by respirometric assays with the optode system (described in section 2.5) and the relative loss of activity was calculated as a percentage according to Eq. 2. Samples for respirometric measurements were taken every two hours, when possible, over 48 hours.

$$
\% \text { Relative loss of activity }=\frac{A_{c}-A_{t}}{A_{c}} \cdot 100
$$

Where: $\mathrm{A}_{\mathrm{c}}=$ activity of the control sample $\left(\mathrm{mg} \mathrm{O}_{2} / \mathrm{L} / \mathrm{h}\right)$

$\mathrm{A}_{\mathrm{t}}=$ activity of the sample with the metal $(\mathrm{mg} / \mathrm{L} / \mathrm{h})$

\subsection{Optode system for oxygen consumption measurements}

The optical oxygen system (FireStingO2, PyroScience GmbH, Germany) was used to measure the oxygen concentration in biological samples, thus determining the activity of the microorganisms. The optode signal was evaluated with a PC using the software Pyro Oxygen Logger v.3.213. Since the fluorescence depends on the temperature, an automatic compensation was performed by a temperature sensor integrated in the optode system. Even so, all the oxygen measurements were taken in a thermostatic bath at $30{ }^{\circ} \mathrm{C}$ to compensate possible temperature fluctuations. According to the manufacturer's indications, the sensor spots were calibrated using air-saturated water $\left(100 \% \mathrm{O}_{2}\right)$ and $2 \%$ w/v sodium sulphite $(0 \%$ $\mathrm{O}_{2}$ ) as references.

For the respirometric measurements, $2 \mathrm{~mL}$ of biological sample was taken and, after the addition of $2 \mathrm{~mL}$ of $6 \mathrm{~K}$ medium, the mixture was vortexed. Then it was transferred to the cuvette of the optode system in 
which the spot sensor had previously been incorporated. The signal was recorded for 30 minutes and, in order to determine the respiration activity, the dissolved oxygen concentration decrease rate was determined.

\section{RESULTS AND DISCUSSION 3.1. PCB composition}

The PCB used herein was digested and analysed to characterize its metal composition. The PCB average content of $\mathrm{Cu}, \mathrm{Ni}, \mathrm{Fe}, \mathrm{Ag}, \mathrm{Au}, \mathrm{Al}, \mathrm{Pd}, \mathrm{In}, \mathrm{Sn}, \mathrm{Pb}, \mathrm{Co}$ and $\mathrm{Mn}$ in g/kg was 390.38, 11.51, 1.95, 0.19, 0.80, $1.33,0.15,0.12,28.92,16.16,0.14$ and 0.58 , respectively. Hence, the total metal content in the PCB was $452.23 \mathrm{~g} / \mathrm{kg}$ of PCB, copper being the major component (39\%). Chen et al. [36] characterized 36 different mobile phones from different companies and year of manufacturing, and they showed that the metal composition of PCB in mobile phones varies considerably depending on the brand, model and year of manufacturing. This variability of metal composition makes the sampling of the E-waste composition analysis difficult [37]. Therefore, it is not possible to generalize the composition of the PCB waste, and it is necessary to analyse the PCB used in bioleaching experiments previously, in order to know its metal composition and to calculate the extraction percentages with accuracy.

\subsection{Copper recovery in column reactor}

Fig. 2 shows the iron (III) and copper concentrations versus time in the bioleachate obtained from the column test described in section 2.3. Results reveal that the highest rate of copper recovery is achieved in the first two hours (practically $90 \%$ of the total copper extracted) and subsequently, the rate drastically decreases. Evolution of iron (III) concentration along time is fully in accordance with copper behaviour. Iron (III) concentration decreased quickly in the first two hours from $5000 \mathrm{mg} / \mathrm{L}$ to little more than 2000 $\mathrm{mg} / \mathrm{L}$ and from this moment, the consumption of this ion slowed down. This behaviour may be associated to mass transfer limitations and the difficulty of access the internal parts of the E-waste. In a first step of two hours, an extremely fast copper uptake takes place due to the easy and rapid utilization of the most readily available extraction sites on the waste particle's surface. Afterwards, a very slow diffusion rate of the metal and a quasi-stationary state takes place.

After 6 hours the extraction percentage of copper was about $50 \%$ but a little more than $1000 \mathrm{mg} / \mathrm{L}$ of iron (III) in the solution remained at the end of the experiment. This behavior is associated to mass transfer limitations and the difficulty for the leaching solution to access to the internal parts of the E-waste. This means that the extraction process does not work perfectly probably due to insufficient contact between the E-waste and the leaching solution. Therefore, improvements have to be implemented to try to increase copper percentage removal. Ilyas et al. [38] also performed the bioleaching of E-waste in a column reactor but using a consortia of Sulfobacillus thermosulfidooxidans. Although they recovered $85 \%$ of copper, they required 165 days to achieve this result. In a study carried out by Chen et al. [15] using a pure culture of Acidithiobacillus ferrooxidans and a column twice the size of the column used in the present study, they extracted $95 \%$ of copper contained in the scrap. Nevertheless, 30 days were needed to achieve this recovery. Hence, although the metal bioleaching in the present study was not completely extracted, the time was significantly reduced from several days to just some hours.

\subsection{Column bioleaching in cycles}

As seen above, around half of the copper initially present in the scrap remained immobilized. Our supposition is that this is due to difficulties in mass transfer and accessibility limitations detected during the operation. For this reason, a new strategy was developed to both increase the velocity of reaction and to overcome accessibility problems for the leaching solution. During column operation, the column filled with e-waste was shaken every two hours, to change the random distribution and avoid dead zones and stagnant regions. With this strategy, the irrigation reaches the entire surface of the e-waste, thus overcoming accessibility problems for the leaching solution. Moreover, the iron (III) solution was also renewed to avoid limiting reagent concentrations during the metal extraction. In a first approach, these two effects were studied separately. 
When only the waste stirring was carried out, after 3 cycles (stirring every two hours for 6 hours' time) copper recovery increased up to $73 \%$. On the other hand, when only the iron renovation was performed, copper recovery did not reach more than 50\% (data not shown). However, when both methodologies were applied simultaneously, copper recovery was considerably increased, reaching $80 \%$ of extraction in 6 hours, as can be seen in Fig. 3. This implies that the new strategy proposed in this study improves the process significantly, since the extraction of copper with this methodology was 1.6 times greater than the extraction obtained by the column reactor in the previous experiment. Results obtained in the present work greatly improved the copper recovery and drastically reduced the time required in comparison to the studies found in the literature focused on column bioleaching. For instance, Chen et al. [15] spent 28 days to achieve $95 \%$ of copper recovery, Ilyas, Lee and Chi needed [38] 16 days to recover $85 \%$ of copper and Jagannath, Vidya Shetty and Saidutta [39] recovered $63.5 \%$ in 5 days. Therefore, in this study, the time was reduced more than 20 times according to some authors [40], and even 100 times [41].

\subsection{Toxicity assays by microrespirometry}

Copper, nickel and aluminium toxicity on Acidithiobacillus ferrooxidans activity was tested using microrespirometry, following the procedure described in section 2.4. All of the respirometric measurements are expressed (Fig 4-5-6-7) as the relative loss of activity when metal is present compared to the biologic activity of the same sample without this metal, according to Eq. 2. The results obtained for copper toxicity are shown in Fig. 4. In general, the relative loss of activity increased when copper concentration increased. This occurred during the 48 hours of the experiment. Moreover, it is noteworthy that the toxic effect was immediate at metal concentrations over $0.6 \mathrm{M}$ whereas at concentrations below $0.05 \mathrm{M}$ there was no effect on biological activity.

In the particular case of $0.80 \mathrm{M}$ of copper, the metal concentration did not turn out to be toxic at the beginning of the experiment but produced a loss of activity later on in time, generating an $87 \%$ of relative loss of activity after 48 hours. Even so, for most of the concentrations the percentage of activity loss increased over time, implying that the contact time between the microorganisms and the toxic metal is a key factor. Considering that the concentration of copper in the PCB bioleaching experiments was $0.05 \mathrm{M}$, it is confirmed that at these conditions microbial metabolism is not negatively affected after 48 hours. Nevertheless, for cases where the biological and leaching steps take place in the same space (e.g. one step bioleaching), it should be noted that copper could be accumulated in long term experiments, reaching toxic concentration levels. After 24 days, results demonstrated that the copper concentration began to reach levels toxic to microorganisms, drastically affecting metabolism after 48 days (considering steadystate copper extraction). However, the limiting time that a metal concentration becomes toxic will mostly depend on the metal extraction obtained in each case. Leduc et al. [30] concluded that the inhibitory concentrations depend on the specific strain of Acidithiobacillus ferrooxidans. Despite of that, Cho et al. [20], who based their study on the inhibition effect of copper on the rate of iron oxidation of Acidithiobacillus ferrooxidans, found that the maximum tolerance concentration for copper was $0.142 \mathrm{M}$. Over this concentration, the complete inhibition of the microorganisms was produced after 42 hours. These results are in agreement with those obtained herein, although the methodology used for determining toxicity was the monitoring of iron (II) consumption instead of the continuous oxygen rate consumption.

The potential toxic effect of nickel on the activity of the iron-oxidizing microorganisms was evaluated at six different concentrations $(0.0005,0.050,0.100,0.300,1.000$ and $1.500 \mathrm{M})$. As shown in Fig. 5, nickel was also toxic to microorganisms after 48 hours, especially at concentrations over $0.3 \mathrm{M}$ in which the effect was immediate. Moreover, the results demonstrated that the concentrations of nickel described in the literature as natural tolerance $(0.3 \mathrm{M})[35]$ are not completely innocuous for microorganisms when the contact with the solution is prolonged for several hours. Although microorganism metabolism has not been disrupted by the concentration of metals in the leachate after one cycle of leaching, the results of this study should be taken into account when designing operation strategies for reducing time in continuous mode. In this sense, long contact times can be avoided by previous separation operations. The observed toxicity effect of nickel is in agreement with Cho et al. [20], who reported that the inhibitory effect of the metal was produced with concentrations over $1.02 \mathrm{M}$, which is the lowest concentration where the toxic 
effect was visible upon contact. However, depending on the total contact time, the negative effect could also be found at concentrations as low as $0.3 \mathrm{M}$ of nickel.

Unlike copper and nickel, aluminium proved toxic at all concentrations tested (Fig. 6). The aluminium toxicity was observed from the beginning of the experiments in all the assays, including the bioleaching concentration $(0.001 \mathrm{M})$. This revealed that this metal was potentially toxic, despite not being included in toxicity studies and being in the leaching medium as a result of the process [20, 41]. Hence, the results corroborate the speculated toxicity of aluminium reported by Brandl, Bosshard and Wegmann [40]. This means aluminium is an important metal to take into account if it is bioleached from scrap, due to its toxic effect to microbial activity over $0.001 \mathrm{M}$, being even more noticeable over $0.05 \mathrm{M}$.

In order to compare the toxicity effect of the three metals studied, three different ion concentrations were considered. On one hand, the bioleaching concentration, which was the average concentration of the metal obtained after the bioleaching process $(0.05,0.0005$ and $0.001 \mathrm{M}$ for $\mathrm{Cu}, \mathrm{Ni}$ and $\mathrm{Al}$, respectively). On the other hand, the concentration referring to the natural and limit reported concentrations were also evaluated. These tolerances were described by Magnin et al. [35] for copper and nickel whereas the aluminium toxicity was studied by Fischer et al. [42].

There are noticeable differences between the three metals. Regarding the natural tolerances, although it was described that they had no effect on the microorganisms' activity, nickel and aluminium produced a negative effect, especially after 48 hours of contact, resulting in an activity loss of $43 \%$ and $19 \%$, respectively. Nevertheless, a natural tolerance concentration of copper did not reduce their activity, which means that they can tolerate it during their growth. In the case of limit tolerances, all the metals have negative effects on the bacteria, generating losses of 50,57 and 93\% of the activity after 48 hours for $\mathrm{Cu}$, $\mathrm{Al}$ and $\mathrm{Ni}$, respectively. Nickel was more toxic than aluminium for the microorganisms, which in turn was more toxic than copper at the same concentration. However, it is evident that aluminium was the most toxic metal during the first 10 hours at the limit tolerance concentration, although the negative effects were visible from the beginning of the experiment in all cases. Therefore, it can be concluded that the contact time between the metals and the microorganisms is crucial during their growth since the longer the time, the more toxic the metal becomes. For this reason, reducing the experimental time of the bioleaching process, as well as the development of the process in two different steps are key considerations for maintaining the activity of microorganisms at their optimal conditions. Regarding bioleaching concentrations, results demonstrated that they were not toxic for the microorganisms since the relative loss of activity was less than $10 \%$ in 48 hours in all cases. However, as stated previously, the accumulation of the metals for longer time operations could cause inactivity to the microorganisms.

\subsection{Microrespirometric tests to define substrate inhibition range}

The inhibitory effect of iron (II) on Acidithiobacillus ferrooxidans was also evaluated using the microrespirometric technique. Six different concentrations of iron (II) were prepared $(0.10,0.20,0.35$, $0.50,0.75$ and $1.00 \mathrm{M}$ ) in which the metal was added as $\mathrm{FeSO}_{4} \cdot 7 \mathrm{H}_{2} \mathrm{O}$. The results were expressed as a percentage of activity loss, as was done in the toxicity assays (see Eq. 2), in which a negative value in relative loss of activity indicates an increase of the microorganisms' activity.

Fig. 7 shows that the iron ions' presence affects microorganisms' activity depending on the metal concentration in the solution. Except in the case of the $0.35 \mathrm{M}$ iron concentration, when the concentration of iron was over $0.20 \mathrm{M}, 40 \%$ of the relative activity was lost from the beginning of the experiment, whereas a $0.10 \mathrm{M}$ concentration increased the activity $6 \%$. This fact implies that high iron concentration reduces the biological activity, inhibiting the metabolism of the microorganisms. Nevertheless, all the tendencies changed after 6 hours. On one hand, the highest iron concentrations evaluated ( 0.75 and 1.00 M) produced a complete loss of activity, corroborating the inhibitory effect of the iron substrate. On the other hand, the lowest concentrations evaluated $(0.10$ and $0.20 \mathrm{M})$ gradually increased the activity of the microorganisms, reaching a peak after 24 hours, higher than the increase achieved with greater iron concentrations. This activity enhancement could be associated to the acclimation of the microorganisms to the new conditions. However, it was observed that the microorganisms adapted easily to high concentrations since the adaption occurred in less than 24 hours. This fact implies an improvement on the iron (III) production, which becomes interesting when the objective is to obtain the maximal productivity of iron (II) oxidation. 
Results demonstrated that the presence of iron at concentrations over $0.75 \mathrm{M}$ negatively affects the activity of the microorganisms. These results are in accordance to those obtained by Kelly and Jones [27], who observed substrate inhibition at concentrations over $0.70 \mathrm{M}$ of iron (II). Nevertheless, conversely to the observation of these authors, inhibitory effects were also observed at concentrations in the range of 0.35 and $0.75 \mathrm{M}$ although the toxicity effect in these cases was reversed after 24 hours by the adaption of the microorganisms to the new conditions. These differences are associated to the conditions and the methodologies used, since Kelly and Jones [27] performed their experiments in a chemostatic culture without taking into account the exposure time of the microorganisms to the inhibited agent. Moreover, at concentrations below $0.16 \mathrm{M}$ no inhibitory effects were observed, as has been previously reported [26-28, 43]. Nevertheless, Barron and Luecking [25] found that the maximal inhibition of growth was produced with an iron (II) concentration of $0.20 \mathrm{~g} / \mathrm{L}(0.35 \mathrm{M})$. Their results differ from those obtained in the present work since at this concentration the growth of cells still occurred. However, the authors did not evaluate how the presence of iron affects the activity of the microorganisms over time, so at the beginning of the experiments in this study, the concentration of $0.35 \mathrm{M}$ of iron really inhibits the biological activity, just as Barron and Lueckling [25] affirmed. Therefore, the exposure time is found to be an important factor to take into account, despite it being ignored in most of the studies focused on the effect of iron (II) to Acidithiobacillus ferrooxidans.

\section{CONCLUSIONS}

In the present study, a new strategy based on bioleaching in cycles in a column reactor has been tested to recover copper from electronic scrap. This technique successfully obtains attractive copper recovery levels (80\%) in a competitive period of time (less than 6 hours).

A microrespirometric technique is presented to evaluate the toxic effect of the main metals present in the leachate on the activity of Acidithiobacillus ferrooxidans. Results show that toxicity depends on the concentration and the exposure time, as well as differences between metals. Aluminium has turned out to be the most toxic metal, producing a complete inhibition of the bacteria activity at a concentration of 0.5 $\mathrm{M}$ in a few minutes of contact. Regarding copper, at the concentration obtained during PCB bioleaching, the results show that microbial metabolism is not affected after $48 \mathrm{~h}$ of exposition. However, in cases where leachate is accumulated (e.g. one step bioleaching or recirculation of continuous mode), toxic concentrations (superior to $0.05 \mathrm{M}$ ) can be reached.

Nickel toxicity tests have shown that, for concentrations greater than $1 \mathrm{M}$, activity inhibition increases with contact time, becoming greater than $90 \%$ after 24 hours. On the contrary, for concentrations lower than $0.1 \mathrm{M}$, no significant effect on the activity was observed. However, for $0.3 \mathrm{M}$, a concentration described in the literature as natural tolerance for Acidithiobacillus ferrooxidans, our findings showed that this concentration affected the microorganism activity by $30 \%$ if the contact time is longer than $24 \mathrm{~h}$. Therefore, it can be concluded that metal exposure time is a key factor to be taken into account in bioleaching processes. The results of the toxicity also reinforce the convenience of performing the biological phase and the chemical oxidation in two different steps during the bioleaching.

Regarding the substrate effect, $\mathrm{Fe}$ (II) concentration over $0.5 \mathrm{M}$ almost completely inhibits the activity of the Acidithiobacillus ferrooxidans after 4 hours of contact. Whereas, at lower concentrations, the inhibitory effect at this time is lower and, furthermore, after eight hours the biological activity increases due to the use of iron as an energy source for bacterial growth.

Strategies developed in the present study on metal bioleaching, combined with the methodology applied for the monitoring activity of the biological process by microrespirometries, provide important data for identifying the limits of the technology application although they also prove how promising this technology can be as an alternative to conventional processes at an industrial scale. 


\section{REFERENCES}

1. Cui, J., Forssberg, E.: Mechanical recycling of waste electric and electronic equipment: A review. J. Hazard. Mater. 99, 243-263 (2003)

2. Hsu, E., Barmak, K., West, A.C., Park, A.H.A.: Advancements in the treatment and processing of electronic waste with sustainability: A review of metal extraction and recovery technologies. Green Chem. 21, 919-936 (2019)

3. Hadi, P., Xu, M., Lin, C.S.K., Hui, C.W., McKay, G.: Waste printed circuit board recycling techniques and product utilization. J. Hazard. Mater. 283, 234-243 (2015)

4. Kasper, A.C., Berselli, G.B.T., Freitas, B.D., Tenório, J.A.S., Bernardes, A.M., Veit, H.M.: Printed wiring boards for mobile phones: Characterization and recycling of copper. Waste Manag. 31, 2536-2545 (2011). https://doi.org/10.1016/j.wasman.2011.08.013

5. Ogunniyi, I.O., Vermaak, M.K.G., Groot, D.R.: Chemical composition and liberation characterization of printed circuit board comminution fines for beneficiation investigations. Waste Manag. 29, 2140-2146 (2009)

6. Dorado, A.D., Solé, M., Lao, C., Alfonso, P., Gamisans, X.: Effect of pH and Fe(III) ions on chalcopyrite bioleaching by an adapted consortium from biogas sweetening. Miner. Eng. 39, 3638 (2012)

7. Khatri, B.R., Sodha, A.B., Shah, M.B., Tipre, D.R., Dave, S.R.: Chemical and microbial leaching of base metals from obsolete cell-phone printed circuit boards. Sustain. Environ. Res. 28, 333-339 (2018)

8. Priya, A., Hait, S.: Extraction of metals from high grade waste printed circuit board by conventional and hybrid bioleaching using Acidithiobacillus ferrooxidans. Hydrometallurgy. 177, 132-139 (2018)

9. Dorado, A.D., Gamisans, X., Sole, M., Lao, C., Benzal, E.: Método para la recuperación biológica de metales en residuos eléctricos y electrónicos. Patent P201830406 (2018)

10. Brierley, C.L.: Bacterial succession in bioheap leaching. Process Metall. 59, 249-255 (2001)

11. Olson, G.J., Brierley, J. a, Brierley, C.L.: Bioleaching review part B: progress in bioleaching: applications of microbial processes by the minerals industries. Appl. Microbiol. Biotechnol. 63, 249-257 (2003)

12. Ilyas, S., Lee, J., Chi, R.: Bioleaching of metals from electronic scrap and its potential for commercial exploitation. Hydrometallurgy. 131-132, 138-143 (2013)

13. Muñoz, J.A., Blázquez, M.L., Ballester, A., González, F.: A study of the bioleaching of a Spanish uranium ore. Part III: Column experiments. Hydrometallurgy. 38, 79-97 (1995)

14. Qiu, G., Li, Q., Yu, R., Sun, Z., Liu, Y., Chen, M., Yin, H., Zhang, Y., Liang, Y., Xu, L., Sun, L., Liu, X.: Column bioleaching of uranium embedded in granite porphyry by a mesophilic acidophilic consortium. Bioresour. Technol. 102, 4697-4702 (2011)

15. Chen, S., Yang, Y., Liu, C., Dong, F., Liu, B.: Column bioleaching copper and its kinetics of waste printed circuit boards (WPCBs) by Acidithiobacillus ferrooxidans. Chemosphere. 141, 162168 (2015). https://doi.org/10.1016/j.chemosphere.2015.06.082

16. Ilyas, S., Ruan, C., Bhatti, H.N., Ghauri, M.A., Anwar, M.A.: Column bioleaching of metals from electronic scrap. Hydrometallurgy. 101, 135-140 (2010)

17. Valix, M.: Bioleaching of Electronic Waste: Milestones and Challenges. En: Current Developments in Biotechnology and Bioengineering. pp. 407-442. Elsevier B.V. (2017)

18. Priya, A., Hait, S.: Comparative assessment of metallurgical recovery of metals from electronic waste with special emphasis on bioleaching. Environ. Sci. Pollut. Res. 24, 6989-7008 (2017)

19. Hagelüken, C., Corti, C.: Recycling of gold from electronics: Cost-effective use through 'design for recycling'. Gold Bull. 43, 209-220 (2010) 
Cho, K.S., Ryu, H.W., Choi, H.M.: Toxicity evaluation of complex metal mixtures using reduced metal concentrations: Application to iron oxidation by Acidithiobacillus ferrooxidans. J. Microbiol. Biotechnol. 18, 1298-1307 (2008)

21. Joshi, V., Shah, N., Wakte, P., Dhakephalkar, P., Dhakephalkar, A., Khobragade, R., Naphade, B., Shaikh, S., Deshmukh, A., Adhapure, N.: Comparative bioleaching of metals from pulverized and non-pulverized PCBs of cell phone charger: advantages of non-pulverized PCBs. Environ. Sci. Pollut. Res. 24, 28277-28286 (2017)

22. Mrážiková, A., Kaduková, J., Marcinčáková, R., Willner, J., Fornalczyk, A., Saternus, M.: The effect of specific conditions on $\mathrm{Cu}, \mathrm{Ni}, \mathrm{Zn}$ and $\mathrm{Al}$ recovery from pcbs waste using acidophilic bacterial strains. Arch. Metall. Mater. 61, 261-264 (2016)

23. Willner, J., Fornalczyk, A.: Extraction of metals from electronic waste by bacterial leaching. Environ. Prot. Eng. 39, 197-207 (2013)

24. Zhan, Y., Yang, M., Zhang, S., Zhao, D., Duan, J., Wang, W., Yan, L.: Iron and sulfur oxidation pathways of Acidithiobacillus ferrooxidans. World J. Microbiol. Biotechnol. 35, 1-12 (2019)

25. Barron, J.L., Luecking, D.R.: Growth and maintenance of Thiobacillus ferrooxidans cells. Appl. Environ. Microbiol. 56, 2801-2806 (1990)

26. Okereket, A., Stevens, S.E.: ferrooxidans Kinetics of Iron Oxidation by Thiobacillus ferrooxidans. Appl. Microbiol. Biotechnol. 57, 1052-1056 (1991)

27. Kelly, D.P., Jones, C.A.: Factors affecting metabolism and ferrous iron oxidation in suspensions and batch cultures of Thiobacillus ferrooxidans: Relevance To Ferric Iron Leach Solution Regeneration. Metallurgical Applications of Bacteria Leaching and Related Microbiological Phenomena 19-44 (1978)

28. Nemati, M., Harrison, S.T.L., Hansford, G.S., Webb, C.: Biological oxidation of ferrous sulphate by Thiobacillus ferrooxidans: A review on the kinetic aspects. Biochem. Eng. J. 1, 171-190 (1998). https://doi.org/10.1016/S1369-703X(98)00006-0

29. Valdés, J., Pedroso, I., Quatrini, R., Dodson, R.J., Tettelin, H., Blake, R., Eisen, J.A., Holmes, D.S.: Acidithiobacillus ferrooxidans metabolism: from genome sequence to industrial applications. BMC Genomics. 9, 597 (2008)

30. Leduc, L.G., Ferroni, G.D., Trevors, J.T.: Resistance to heavy metals in different strains of Thiobacillus ferrooxidans. World J. Microbiol. Biotechnol. 13, 453-455 (1997)

31. Braunschweig, J., Bosch, J., Heister, K., Kuebeck, C., Meckenstock, R.U.: Reevaluation of colorimetric iron determination methods commonly used in geomicrobiology. J. Microbiol. Methods. 89, 41-48 (2012)

32. Adhapure, N.N., Dhakephalkar, P.K., Dhakephalkar, A.P., Tembhurkar, V.R., Rajgure, A. V., Deshmukh, A.M.: Use of large pieces of printed circuit boards for bioleaching to avoid 'precipitate contamination problem' and to simplify overall metal recovery. MethodsX. 1, 181-186 (2014)

33. Giebner, F., Kaschabek, S., Schopf, S., Schlömann, M.: Three adapted methods to quantify biomass and activity of microbial leaching cultures. Miner. Eng. 79, 169-175 (2015)

34. Jeffery, G.H., Bassett, J., Mendham, J., Denney, R.C.: Vogel's textbook of quantitative chemical analysis. 5th ed. Longman Scientific \& Technical, England (1989)

35. Magnin, J., Bailet, F., Boyer, A., Zlatev, R., Luca, M., Cheruy, A., Ozil, P.: Augmentation, par régéneration électrochimique du substrat, de la production d'une biomasse (Thiobacillus ferrooxidans DSM 583) pour un procédé biologique de récupération de métaux. Can. J. Chem. Eng. 76, 978-984 (1998)

36. Chen, Y., Chen, M., Li, Y., Wang, B., Chen, S., Xu, Z.: Impact of technological innovation and regulation development on e-waste toxicity: A case study of waste mobile phones. Sci. Rep. 8, 1$9(2018)$

37. Khaliq, A., Rhamdhani, M.A., Brooks, G., Masood, S.: Metal extraction processes for electronic 
waste and existing industrial routes: A review and Australian perspective. Resources. 3, 152-179 (2014)

3 38. Ilyas, S., Lee, J., Chi, R.: Bioleaching of metals from electronic scrap and its potential for commercial exploitation. Hydrometallurgy. 131-132, 138-143 (2013)

39. Jagannath, A., Vidya Shetty, K., Saidutta, M.B.: Bioleaching of copper from electronic waste using Acinetobacter sp. Cr B2 in a pulsed plate column operated in batch and sequential batch mode. J. Environ. Chem. Eng. 5, 1599-1607 (2017)

40. Brandl, H., Bosshard, R., Wegmann, M.: Computer-munching microbes: metal leaching from electronic scrap by bacteria and fungi. Hydrometallurgy. 59, 319-326 (2001)

41. David, D.J., Pradhan, D., Das, T.: Evaluation of iron oxidation rate of Acidithiobacillus ferrooxidans in presence of heavy metal ions. Trans. Institutions Min. Metall. Sect. C Miner. Process. Extr. Metall. 117, 56-61 (2008)

42. Fischer, J., Quentmeier, A., Gansel, S., Sabados, V., Friedrich, C.G.: Inducible aluminum resistance of Acidiphilium cryptum and aluminum tolerance of other acidophilic bacteria. Arch. Microbiol. 178, 554-558 (2002)

43. Pagnanelli, F., Luigi, M., Mainelli, S., Toro, L.: Use of natural materials for the inhibition of iron oxidizing bacteria involved in the generation of acid mine drainage. Hydrometallurgy. 87, 27-35 (2007) 